\title{
Tobacco, Alcohol and Family History of Cancer as Risk Factors of Oral Squamous Cell Carcinoma: Case-Control Retrospective Study
}

\author{
Gianluca Tenore ${ }^{1,2} \mathbb{D}$, Alessandro Nuvoli ${ }^{1,2}$, Ahmed Mohsen ${ }^{1,2}, *(\mathbb{D})$, Andrea Cassoni ${ }^{1,2}$, \\ Andrea Battisti 1,2, Valentina Terenzi ${ }^{1,2}$, Marco Della Monaca 1,2, Ingrid Raponi ${ }^{1,2}{ }^{\mathbb{D}}$, \\ Edoardo Brauner 1,2 (D), Francesca De Felice ${ }^{1,3}$, Daniela Musio ${ }^{1,3}$,

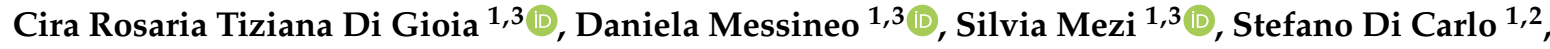 \\ Andrea Botticelli ${ }^{1,4}$, Valentino Valentini ${ }^{1,2}$, Paolo Marchetti ${ }^{1,4}$, Vincenzo Tombolini ${ }^{1,3}$, \\ Marco De Vincentiis ${ }^{1,2}$, Antonella Polimeni ${ }^{1,2} \mathbb{D}$ and Umberto Romeo ${ }^{1,2} \mathbb{D}$ \\ 1 Head and Neck Tumor Board, Polyclinic Umberto I, Sapienza University of Rome, 00161 Rome, Italy; \\ gianluca.tenore@uniroma1.it (G.T.); nuvoli.alessandro@gmail.com (A.N.); \\ andrea.cassoni@uniroma1.it (A.C.); andrea.battisti@uniroma1.it (A.B.); valentina.terenzi@uniroma1.it (V.T.); \\ marco.dellamonaca@uniroma1.it (M.D.M.); ingrid.raponi@uniroma1.it (I.R.); \\ edoardo.brauner@uniroma1.it (E.B.); francesca.defelice@uniroma1.it (F.D.F.); \\ daniela.musio@uniroma1.it (D.M.); cira.digioia@uniroma1.it (C.R.T.D.G.); \\ daniela.messineo@uniroma1.it (D.M.); silvia.mezi@uniroma1.it (S.M.); stefano.dicarlo@uniroma1.it (S.D.C.); \\ andrea.botticelli@uniroma1.it (A.B.); valentino.valentini@uniroma1.it (V.V.); \\ paolo.marchetti@uniroma1.it (P.M.); vincenzo.tombolini@uniroma1.it (V.T.); \\ marco.devincentiis@uniroma1.it (M.D.V.); antonella.polimeni@uniroma1.it (A.P.); \\ umberto.romeo@uniroma1.it (U.R.) \\ 2 Department of Oral Sciences and Maxillofacial Surgery, Sapienza University of Rome, 00161 Rome, Italy \\ 3 Department of Radiological Sciences, Oncology and Anatomical Pathology, Sapienza University of Rome, \\ 00161 Rome, Italy \\ 4 Department of Clinical and Molecular Medicine, Sapienza University of Rome, 00161 Rome, Italy \\ * Correspondence: ahmed.mohsen@uniroma1.it; Tel./Fax: +39-0649918165
}

Received: 14 May 2020; Accepted: 1 June 2020; Published: 4 June 2020 updates

Abstract: The aim of the study is to observe retrospectively the correlation between Oral Squamous Cell Carcinoma (OSCC) and risk factors; including tobacco, alcohol and Family History of Cancer (FHC). A total of 478 patients were included retrospectively from the database of the Department of Oral Sciences and Maxillofacial Surgery, Sapienza University of Rome. A Test Group (TG) consisted of 239 patients with a confirmed diagnosis of OSCC. A Control Group (CG) consisted of 239 patients without history and/or diagnosis of oral cancer. The logistic regression models were used to calculate the adjusted Odd Ratios (ORs) associated with alcohol, tobacco and FHC; including the General Family History of Cancer (GFHC) and Family History of Head and Neck Cancer (FHHNC) and their 95\% Confidence Intervals (CI). The high rate of tobacco consumption was associated with an OR of $1.035(95 \%$ CI 1.001-1.070) and a statistical significance $(p=0.041)$. Drinker patients showed a significant risk of developing OSCC ( $p=0.05)$ and the OR was 1.035 (95\% CI 1.010-1.061). The GFHC was associated with a marginal risk of OSCC with an OR of 1.095 (95\% CI 0.953-1.259), without significance $(p=0.199)$. The FHHNC showed a notable risk increase with an OR of 1.871 (95\% CI $0.902-3.882)$, without significance $(p=0.092)$. Alcohol and tobacco may be associated with an increase in the risk of OSCC.

Keywords: alcohol; family history of cancer; head and neck cancer; oral cancer; oral squamous cell carcinoma; smoking; tobacco 


\section{Introduction}

Oral Squamous Cell Carcinoma (OSCC) represents 90\% of lip and oral cancers. OSCC is considered the twelfth most prevalent cancer worldwide. Lip and oral cancer, as one of the Head and Neck Cancers (HNCs) subtypes, is considered the 16th most commonly diagnosed cancer worldwide in both sexes. In 2018, the annual estimated number of incident cases with oral and lip cancer was 354,864 cases worldwide and 3967 cases in Italy. The annual estimated number of deaths due to oral and lip cancer was 177,384 cases worldwide and 1489 cases in Italy [1-4].

The exact pathogenesis of HNCs is not fully clear. It has been suggested to consider HNCs as complex multifactorial disorders [5]. Since cancer cells show genetic damage (e.g., gene mutations) that may be resulted from exposure to carcinogens, it is recommended to study different carcinogens and to understand the associated risk factors in order to plan preventive and management measures of this disease [6,7].

Many risk factors have been linked to oral cancer; such as human papillomavirus infection [8], local chronic trauma [9], exposure to ultraviolet radiations [10], low-antioxidants diet [11], immunosuppression [6] and Oral Potentially Malignant Lesions (OPMLs) [12]. Tobacco smoking and alcohol consumption are the most common associated risk factors of OSCC. They are the major risk factors in $74 \%$ of cases with OSCC in the western world [13].

Tobacco products are responsible for causing a variety of cancers including the oral cavity due to the exposure to carcinogens contained in tobacco products. More than 60 known carcinogens in smoke tobacco and about 16 in unburned tobacco have been detected. The concentration and potency of these carcinogens vary according to the type of tobacco product and its method of consumption. In several studies, sufficient evidence has been provided for the carcinogenicity of many of these detected carcinogens; such as tobacco-specific nitrosamines, polycyclic aromatic hydrocarbons and aromatic amines [14].

Alcohol is directly related to $4.2 \%$ of cancer deaths worldwide [15]. Alcohol is linked to $26.4 \%$ of all lip and oral cavity cancers worldwide [16]. The main metabolites of ethanol are considered as a class 1 carcinogen [5,17]. These metabolites play a direct effect in carcinogenesis by causing a disturbance of DNA synthesis and repair, formation of DNA adducts and alteration of oncogenes expression by DNA hypomethylation [18]. In addition, alcohol metabolites have an indirect role through acting as a solvent and making the mucosa more permeable to other carcinogens such as tobacco carcinogens [17].

There are conflicting opinions on the role of Family History of Cancer (FHC) on oral cancers. Some authors believe that there is no evidence of a clear hereditary trait for oral cancers, since different hereditary cancer syndromes, except for some Cowden Syndrome cases, have not been reported with oral cancers [6]. Several epidemiological studies have assessed the familial risks for oral cancers. Many of them have suggested the possible correlation between FHC and oral cancer [19-22].

The variation in the strength of association of tobacco and alcohol with oral cancers among previous studies and the presence of conflicting opinions in considering the FHC as a risk factor of oral cancers, have signified the need for further studies for comparison.

This study is carried out to observe retrospectively the association of tobacco and alcohol with OSCC. In addition, the correlation between OSCC and Family History of Cancer (FHC) is analyzed through observing the Family History of Head and Neck Cancer (FHHNC) and General Family History of Cancer (GFHC); including the First-Degree Family History (FDFH) and Second-Degree Family History (SDFH).

\section{Materials and Methods}

A case-control retrospective study was carried out on patients enrolled in a task force called the MoMax (Oral Medicine and Maxillofacial Surgeon) project of the Department of Oral Sciences and Maxillofacial Surgery, Sapienza University of Rome; in this task force, oral medicine specialists, prosthodontists, maxillofacial surgeons, oncologists, radiotherapists and histo-pathologists collaborate to provide cancer patients with multidisciplinary team care. Informed consent was obtained from all 
individual participants included in the study. All the study procedures were performed in accordance with the ethical standards of the institutional and/or national research committee and with the 1964 Helsinki declaration and its later amendments or comparable ethical standards.

\subsection{Data Collection}

The patients were recruited retrospectively from the department's database from 2000 to 2018. The inclusion criteria were patients with a confirmed diagnosis of oral cancer with epithelial origin (OSCC) and age $\geq 18$ years. Patients with cancers outside the oral cavity, with other types of oral cancers, and/or with age $<18$ years were excluded from the study.

A total of 262 patients were found and were fulfilling the inclusion criteria of the study. The medical recordings of twenty-three patients were incomplete. Therefore, these patients were excluded from the study. The remaining 239 patients (125 females and 114 males) with an average age of 65.56 years, were recruited in the Test Group (TG). The site of OSCC was registered according to the 10th edition of the International Classification of Diseases (ICD-10) version 2010 [23]. The oral cavity was described as follow; tongue (C02.3), superior alveolar ridge mucosa (C03.0), palate (C05.9), inferior alveolar ridge mucosa (C03.1), tonsillar pillar (C09.1), buccal mucosa (C06.0), the floor of the mouth (C04.9), oral vestibule (C06.1) and lips (C00.5).

A total of 239 patients (123 females and 116 males) with no history and/or diagnosis of oral cancer, were recruited in the Control Group (CG). The patients were selected from the department database with the same age interval, average age, age distribution and time window of the TG to compare the obtained results. The collected data for both groups were as follows; age, gender, tobacco status and consumption amount, alcohol status and consumption amount and FHC.

For the analysis of tobacco, the patients were categorized into non-smokers and smokers. Patients who stopped smoking for more than 10 years, were considered non-smokers. The tobacco consumption amount was measured in pack years. The tobacco consumption amount was divided into three categories; $\leq 20$ pack years, $21-40$ pack years and $>40$ pack years.

To analyze the alcohol, the patients were categorized into non-drinkers and drinkers. The type of alcohol was described in three categories; wine, beer and spirit. The alcohol consumption amount was measured in drinks/week. The patients were divided into three groups according to the quantity of alcohol consumption; $<7$ drinks/week, 7-10 drinks/week and $>10$ drinks/week. Patients with alcohol abuse issues were documented.

The FHC was categorized into General Family History of Cancer (GFHC) and Family History of Head and Neck Cancer (FHHNC). The degree of kinship was also considered, where the GFHC was categorized into First-Degree Family History (FDFH) and Second-Degree Family History (SDFH). The FDFH included parents, full siblings and children. The SDFH included grandparents, aunts/uncles and cousins.

\subsection{Statistical Analysis}

All the obtained results were registered in an Excel sheet using Office 365 (Microsoft Corporation, Redmond, WA, USA). The data were analyzed with SPSS software (Statistical Package for Social Science) for Windows, release 20.0.

A descriptive analysis was carried out including all the considered variables in the study; gender, age, tobacco status and consumption amount, alcohol status and consumption amount and FHC (GFHC, FHHNC, FDFH and SDFH). Logistic regression models were used to calculate the adjusted Odd Ratios (ORs) and their 95\% Confidence Intervals (CI); to understand the role of each potential risk factor in the development of OSCC. A statistically significant difference was considered when $p$-value $<0.05$. The logistic regression model was controlled for tobacco status and consumption, alcohol status and consumption, GFHC, FHHNC, FDFH and SDFH. 


\section{Results}

The patients' preview and characteristics are presented in Table 1 . The most frequent affected site by OSCC was the tongue (C02.3) in 84 patients $(35.1 \%)$. The second most frequent site was the inferior alveolar ridge mucosa (C03.1) in 43 patients (18\%). The least frequent site was the oral vestibule (C06.1) in 1 patient $(0.4 \%)$ (Figure 1$)$.

Table 1. Patients' preview and characteristics.

\begin{tabular}{cccc}
\hline Characteristics & Test Group & Control Group & Total \\
\hline Average Age & 65.56 & 65.75 & 65.66 \\
Age & $\mathrm{n}(\%)$ & $\mathrm{n}(\%)$ & $\mathrm{n}(\%)$ \\
550 & $41(17.2)$ & $19(7.9)$ & $60(12.6)$ \\
$50-65$ & $69(28.9)$ & $96(40.2)$ & $165(34.5)$ \\
$>80$ & $90(37.6)$ & $96(40.2)$ & $186(38.9)$ \\
Gender & $39(16.3)$ & $28(11.7)$ & $67(14)$ \\
Male & & & \\
Female & $114(48)$ & $116(49)$ & $230(48)$ \\
Tobacco Status & $125(52)$ & $123(51)$ & $248(52)$ \\
Non-smokers & & & \\
Smokers & $103(43.1)$ & $118(49.4)$ & $221(46.2)$ \\
$\leq 20$ & $136(56.9)$ & $121(50.6)$ & $257(53.8)$ \\
$21-40$ & & & \\
$>40$ & $52(21.8)$ & $47(19.7)$ & $99(20.7)$ \\
Tobacco consumption amount (pack years) & $46(19.2)$ & $40(16.7)$ & $86(18)$ \\
Alcohol Status & $38(15.9)$ & $34(14.2)$ & $72(15.1)$ \\
Non-drinkers & & & \\
Drinkers & $125(52.3)$ & $144(60.3)$ & $269(56.3)$ \\
$<7$ & $114(47.7)$ & $95(39.7)$ & $209(43.7)$ \\
$7-10$ & & & \\
$>10$ & $21(8.8)$ & $31(13)$ & $52(10.9)$ \\
Alcohol abuse & $35(14.6)$ & $29(12.1)$ & $64(13.4)$ \\
Alcohol consumption amount (drinks/week) & $58(24.3)$ & $35(14.6)$ & $93(19.4)$ \\
& $12(5)$ & $0(0)$ & $12(2.5)$ \\
\hline
\end{tabular}

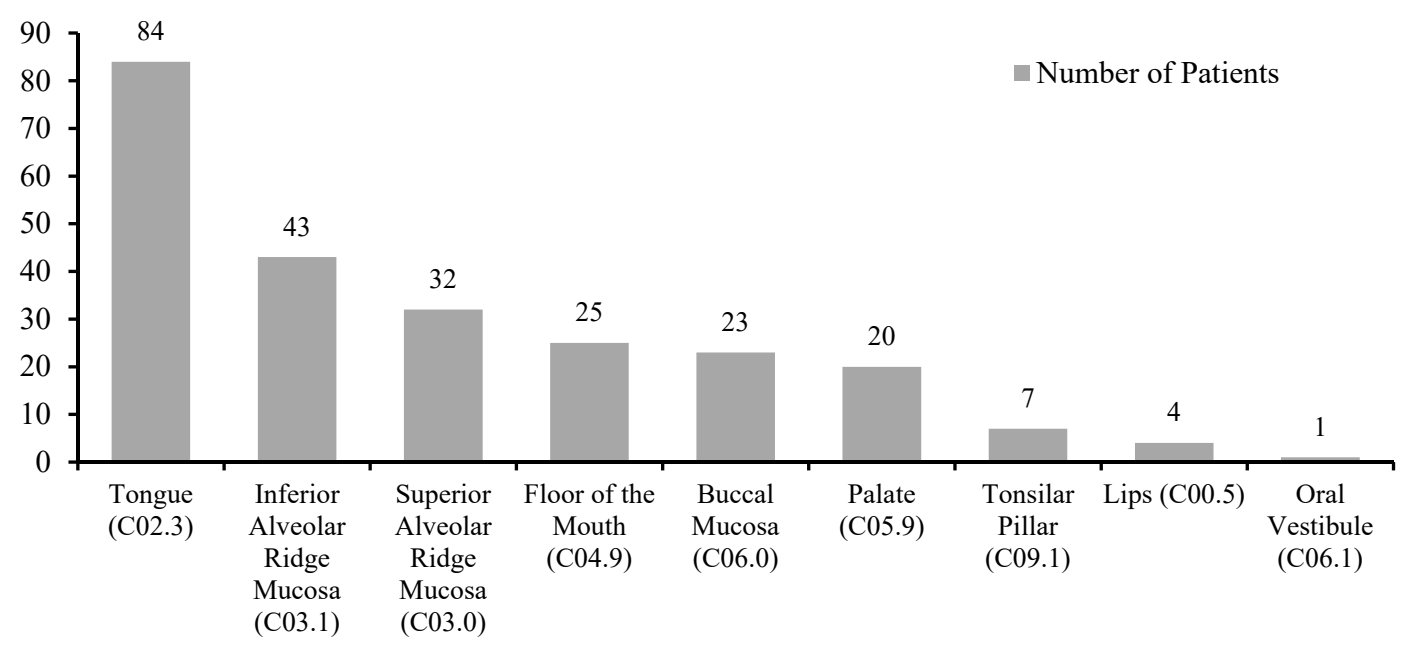

Figure 1. Distribution of cases according to the sites of Oral Squamous Cell Carcinoma (OSCC) defined by the 10th edition of the International Classification of Diseases (ICD-10) version 2010 in the Test Group (TG). 
Approximately $46.2 \%$ of the study participants were non-smokers. In the TG, the number of smokers $(n=136)$ was slightly higher than that of CG $(n=121)$. No statistical significance was observed in regard to the smoking status with OR of 1.004 (95\% CI 0.996-1.012) and $p=0.294$.

Among the smokers, the average of tobacco consumption in TG was 20.6 pack years and in CG it was 15.1 pack years (Table 2). The high rate of tobacco consumption ( $>40$ pack years) showed an associated risk with OR of $1.035(95 \%$ CI 1.001-1.070) and statistical significance ( $p=0.041)$ where the risk increased with patients with high rate of tobacco consumption ( $>40$ pack years).

Table 2. Average tobacco and alcohol consumption in both groups.

\begin{tabular}{cccc}
\hline Variable & $\begin{array}{c}\text { Test Group } \\
\text { (Average) }\end{array}$ & $\begin{array}{c}\text { Control Group } \\
\text { (Average) }\end{array}$ & $\begin{array}{c}\text { Total } \\
\text { (Average) }\end{array}$ \\
\hline Tobacco consumption (pack years) & 20.6 & 15.1 & 17.81 \\
Alcohol consumption (drinks/week) & 7.4 & 3.7 & 5.55 \\
\hline
\end{tabular}

Approximately $56.3 \%$ of all the participants $(n=269)$ were non-drinkers $(125$ patients of TG $(52.3 \%)$ and 144 patients of CG $(60.3 \%)$. The wine was the most frequent alcohol beverage in 185 patients $(38.7 \%)$ (Table 3). The average alcohol consumption in TG was 7.4 drinks/week and in CG it was 3.7 drinks/week. Among the drinkers, it was observed that the alcohol consumption amount was 1 drink per day or less ( $\leq 7$ drinks/week) in 86 patients (41.2\%) and the alcohol consumption was 2 drinks per day (14 drinks/week) in 62 patients $(29.7 \%)$, while the alcohol consumption in the rest $(n=61)$ of drinkers $(29.1 \%)$ was more than 2 drinks per day. The presence of a history of alcohol abuse was observed in 12 patients of the TG $(5 \%)$.

Table 3. Distribution of alcohol types in the study.

\begin{tabular}{cc}
\hline Alcohol Type & $\begin{array}{c}\text { Total } \\
\text { n (\%) }\end{array}$ \\
\hline None & $269(56.3)$ \\
Wine & $185(38.7)$ \\
Beer & $11(2.3)$ \\
Wine \& Spirit & $5(1.1)$ \\
Wine \& Beer & $4(0.8)$ \\
Spirit & $2(0.4)$ \\
Wine, Beer \& Spirit & $2(0.4)$ \\
\hline
\end{tabular}

The calculated ORs for tobacco and alcohol are presented in Table 4. Drinker patients showed a significant associated risk of developing OSCC $(p=0.05)$ and with OR $=1.035$ (95\% CI 1.010-1.061). No significance was observed in regard to the alcohol consumption amount. However, it was observed that the OR increase with the increase of alcohol consumption amount as the OR was 0.941 (95\% CI $0.615-1.437)$ in patients who drink $<7$ drinks/week $(p=0.777)$, the OR increased to 1.021 (95\% CI $0.359-2.905)$ in patients who drink $7-10$ drinks/week $(p=0.969)$ and a further increase of the OR to 1.051 (95\% CI 0.989-1.116) was observed in patients who drink $>10$ drinks/week $(p=0.111)$. 
Table 4. Odd Ratios (ORs) for tobacco and alcohol.

\begin{tabular}{ccccc}
\hline Variable & $\begin{array}{c}\text { Test Group } \\
\mathbf{n}\end{array}$ & $\begin{array}{c}\text { Control Group } \\
\mathbf{n}\end{array}$ & OR (95\% CI) * & $p$ Value $<0.05$ \\
\hline $\begin{array}{c}\text { Tobacco Status } \\
\text { Non-Smokers }\end{array}$ & 103 & 118 & 1 & \\
$\quad \begin{array}{c}\text { Smokers } \\
\text { Tobacco consumption } \\
\text { amount (pack years) }\end{array}$ & 136 & 121 & $1.004(0.996-1.012)$ & 0.294 \\
$\leq 20$ & & & & \\
$21-40$ & 52 & 47 & $0.991(0.929-1.059)$ & 0.798 \\
$>40$ & 46 & 40 & $1.002(0.920-1.091)$ & 0.960 \\
$\begin{array}{c}\text { Alcohol Status } \\
\text { Non-drinkers }\end{array}$ & 38 & 34 & $1.035(1.001-1.070)$ & $0.041^{* *}$ \\
Drinkers & 125 & 144 & & \\
Alcohol consumption & 114 & 95 & $1.035(1.010-1.061)$ & $0.05 * *$ \\
amount (drinks/week) & & & & \\
$<7$ & 21 & 31 & $0.941(0.615-1.437)$ & 0.777 \\
$7-10$ & 35 & 29 & $1.021(0.359-2.905)$ & 0.969 \\
$>10$ & 58 & 35 & $1.051(0.989-1.116)$ & 0.111 \\
\hline
\end{tabular}

${ }^{*}$ OR adjusted for age, tobacco (pack years), alcohol (drinks/week), general family history of cancer, ${ }^{* *} p<0.05$.

The GFHC was associated with a marginal risk of OSCC with an OR of 1.095 (95\% CI 0.953-1.259), without significance $(p=0.199)$ (Table 5$)$. The FHHNC showed a notable associated risk with an OR of 1.871 (95\% CI 0.902-3.882), without significance $(p=0.092)$. The FDFH had an OR of $1.154(95 \%$ CI 0.949-1.403), without significance ( $p=0.152)$. The SDFH had an OR of 1.039 (95\% CI 0.853-1.266), without significance $(p=0.706)$.

Table 5. Odd Ratios (ORs) for Family History of Cancer.

\begin{tabular}{|c|c|c|c|c|}
\hline Variable & $\begin{array}{l}\text { Test Group } \\
\mathbf{n}\end{array}$ & $\begin{array}{c}\text { Control Group } \\
\mathbf{n}\end{array}$ & OR $(95 \% \mathrm{CI}) *$ & $p$ Value $<0.05$ \\
\hline \multicolumn{5}{|c|}{$\begin{array}{l}\text { General Family History of } \\
\text { Cancer }\end{array}$} \\
\hline Without & 90 & 93 & 1 & \\
\hline With & 149 & 146 & $1.095(0.953-1.259)$ & 0.199 \\
\hline \multicolumn{5}{|c|}{ First Degree Family } \\
\hline \multicolumn{5}{|l|}{ History } \\
\hline Without & 117 & 128 & 1 & \\
\hline With & 122 & 111 & $1.154(0.949-1.403)$ & 0.152 \\
\hline \multicolumn{5}{|c|}{ Second Degree Family } \\
\hline \multicolumn{5}{|l|}{ History } \\
\hline Without & 180 & 179 & 1 & \\
\hline With & 59 & 60 & $1.039(0.853-1.266)$ & 0.706 \\
\hline \multicolumn{5}{|c|}{$\begin{array}{l}\text { Family History of Head } \\
\text { and Neck Cancer }\end{array}$} \\
\hline Without & 220 & 228 & 1 & \\
\hline With & 19 & 11 & $1.871(0.902-3.882)$ & 0.092 \\
\hline
\end{tabular}

* OR adjusted for age, tobacco (pack years), alcohol (drinks/week), general family history of cancer.

The distribution of patients according to the number of affected relatives are presented in Table 6. TG showed relatively more patients with increased number of relatives affected by cancer. 
Table 6. Distribution of patients according to the number of affected relatives.

\begin{tabular}{cccc}
\hline Number of Affected Relatives & $\begin{array}{c}\text { Test Group } \\
\mathbf{n}(\mathbf{\%})\end{array}$ & $\begin{array}{c}\text { Control Group } \\
\mathbf{n}(\mathbf{\%})\end{array}$ & $\begin{array}{c}\text { Total } \\
\mathbf{n}(\mathbf{\%})\end{array}$ \\
\hline General Family History of Cancer & & & \\
None & $90(37.6)$ & $93(38.9)$ & $183(38.3)$ \\
1 & $74(31)$ & $80(33.5)$ & $154(32.2)$ \\
2 & $41(17.2)$ & $39(16.3)$ & $80(16.7)$ \\
$\geq 3$ & $34(14.2)$ & $27(11.3)$ & $61(12.8)$ \\
Family History of Head and Neck Cancer & & & \\
None & $220(92.1)$ & $228(95.4)$ & $448(93.7)$ \\
1 & $18(7.5)$ & $11(4.6)$ & $29(6.1)$ \\
2 & $0(0)$ & $0(0)$ & $0(0)$ \\
$\geq 3$ & $1(0.4)$ & $0(0)$ & $1(0.2)$ \\
\hline
\end{tabular}

\section{Discussion}

The association of tobacco and alcohol with the risk of oral cancer was demonstrated by several studies $[17,18,24-26]$. Our study demonstrated that the correlation between tobacco and risk of OSCC increased significantly with higher tobacco consumption amount ( $>40$ pack years). A significant increase in the risk of developing OSCC was observed in drinker patients. In addition, the risk increased with the increase of alcohol consumption but without significance.

A multicenter case-control study was carried out on 10 European countries including Italy for observing the association of tobacco and alcohol with the risk of upper aerodigestive tract cancer. The OR for tobacco was 2.37 for the oral cavity. While the OR for alcohol was 1.04 [27]. A hospital-based case-control study carried out in Northern Italy for observing the associated risk of both tobacco and alcohol with different head and neck cancers. The OR for tobacco was 11.1 for the oral cavity. The OR was 4.9 for heavy wine drinkers ( $\geq 56$ glasses/week) rising to 8.5 for drinkers of $\geq 84$ glasses/week [28]. While in our study, the OR for tobacco was 1.004. The OR for mild smokers was 0.991 ( $\leq 20$ pack years) and increased significantly to 1.035 for heavy smokers ( $>40$ pack years). The OR for alcohol was 1.035. The OR was 0.941 in drinker patients who drink less than 7 drinks/week and increased to 1.051 in drinker patients who drink more than 10 drinks/week.

In our study, the strength of the association of tobacco and alcohol with oral cancer was not as much as described in the literature. It was observed the presence of variation in the strength of tobacco and alcohol risk factors for oral cancer among previous studies [27]. There are several reported issues regarding these risk factors that should be considered for the interpretation of the studies' findings.

The contribution of alcohol and tobacco as risk factors of HNCs varies among different countries and geographical areas. A pooled analysis demonstrated that population attributable risks for both tobacco and alcohol differed among regions, where tobacco and alcohol were considered being responsible for $84 \%$ of all HNCs in Europe and the value decreased to $51 \%$ of all HNCs in the North America [29].

In a study on the East Asian population, the association of tobacco with the risk of HNCs was relatively low when compared to other similar studies on populations of the United States and Europe. The authors suggested that this variation may be due to the difference in smoking patterns, chemical characteristics of tobacco and/or genetic factors [30]. This suggestion was based on that the concentration of carcinogens in tobacco products may vary according to tobacco products origin. Where, the International Agency for Research on Cancer (IARC) found that the concentration range of nitrate, nicotine and tobacco-specific $\mathrm{N}$-nitrosamines in commercial cigarettes was higher in the United States when compared to those in Japan [31].

The association of tobacco with the risk of cancer may differ among the HNC subtypes [5]. In some studies, it was demonstrated that smoking had a stronger association with larynx and pharynx than the oral cavity $[5,32]$. This may be due to the higher exposure of larynx and pharynx to smoke than the oral cavity [5]. 
The benefit of smoking cessation may be a time-dependent benefit. It was found that the risk of oral cancer among non-smokers was similar to former smokers after 10 years of smoking cessation. In addition, smoking cessation after or in middle age might dramatically decrease the risk of oral cancer $[24,33]$. In our study, former smokers who stopped smoking for more than 10 years, were considered non-smokers.

The link between alcohol and HNC seems to be dose-related. The association of alcohol with the risk of oral cancer may differ according to the drinking pattern; including the type, number and frequency of drinks $[30,34]$. The highest incidence and mortality of oral cancer was shown in Eastern European populations where the consumption of spirits was higher than in other populations [35]. Mashberg et al. analyzed risk factors for oral and oropharyngeal cancers on male patients. They found that the OR increased in patients consuming more than 21 whiskey equivalents per day, which were considerable amounts [36]. In contrast, approximately $88.5 \%$ of the drinker patients in our study were consuming only wine. In addition, the majority of patients were consuming low to medium wine quantities, ranging from 0.5 to 2 glasses of wine per day at mealtime.

The dietary habit was reported as an issue to be considered in the alcohol risk analysis. Wine is usually consumed at mealtime in the Mediterranean area. There was reported evidence that demonstrated health-promoting effects related to low and moderate red wine at mealtimes [34,37]. In a systemic review, protection against certain cardiovascular diseases and reduction of morbidity and mortality were associated with this nutritional habit [38].

There are two xenobiotics in wine; ethanol and phytochemicals. Phytochemicals are beneficial bioactive compounds [34]. Since a reduced risk of cancer was associated with the high fruit and vegetable consumption, this dietary habit may promote health benefits through the synergetic effect between phytochemicals contained in wine and nutraceuticals of consumed fruits and vegetables $[39,40]$. Studies demonstrated the reduction of incidence rates for lip and oral cancer in Mediterranean countries (e.g. Italy) where consuming red wine is common with a healthy diet $[34,35]$.

In order to overcome a repeated drawback in the way of reporting the total volume of ethanol intake, it was proposed a standard drinks unit for each country from which the gram (g) of ethanol can be calculated for each drink. The standard unit for a drink in Italy was equal to $12 \mathrm{~g}$ of ethanol [34]. According to this proposed standard drink unit, $70.9 \%$ of the participants of this study were consuming $\leq 24 \mathrm{~g}$ of ethanol per day.

The literature suggested that the self-report tools for the collection of data of alcohol intake was valid. It was verified that self-report tools gave similar data when compared to other objective measures of alcohol intake; such as transdermal alcohol sensors. However, there are still concerns about the design of the questions for obtaining the data to avoid social desirable responses [16].

No statistical significance was observed in this study in regard to the FHC as a risk of OSCC. However, all the considered variables of the FHC (GFHC, FHHNC, FDFH, SDFH) were associated with an OR greater than 1 . The highest OR was observed with the FHHNC (OR $=1.871)$.

Almost all the performed studies on this issue demonstrated similar results [41-44]. Goldstein et al. found that the OR of GFHC was 1.1 and the OR of the family history of oropharyngeal cancers was 1.2 [21]. In a multicenter study, the estimated OR was 2.6 for family history of oral and pharyngeal cancer [19]. In a study, the ORs were calculated and pooled from 12 studies. It was found that the OR of FHHNC was 1.7 [44]. Foulkes et al. found that the Relative Risk (RR) of developing a HNC was 1.97 in patients with FDFH and the RR increased to 3.65, in case the FDFH was of head and neck cancer [43]. In another study, the OR was 1.28 in patients with a FDFH of any type of cancer. The risk increased with the increase of affected relatives number [41].

In the literature, there is a controversy to consider the FHC as a risk factor of oral cancer or not. Some authors were against because there were no hereditary cancer syndromes that showed oral cancers except some Cowden Syndrome cases [6]. Others suggested considering the FHC as a risk factor of oral cancer. This suggestion was based on the presence of case reports with multiple affected members, the presence of epidemiological studies that indicate the presence of a familial tendency 
to oral cancer, the presence of increased risks associated with polymorphic genes implicated in the metabolism of alcohol and tobacco and the presence of increased risks associated with genes implicated in DNA repair maintenance of genetic stability [19].

Many studies showed the familial aggregation of oral cancer. It was attributed to be possibly due to the presence of genetic factors or environmental factors that make the relatives having similar reflection to specific risk factors such as tobacco and/or alcohol $[19,20]$. This explanation of the familial aggregation could be observed in a study, which showed that the risk of oral cancer increased in patients with a family history of lung cancers that is highly associated with tobacco risk factor. However, the risk of oral cancers did not increase in patients with a family history of other cancers associated with tobacco or alcohol such as esophagus or liver cancers [19,28,45].

Some limitations were observed in our study that should be acknowledged. First, the study was a hospital-based study where the control group consisted of attended patients to our department. Second, the data of family history were collected through the self-recall method. According to the literature, the self-recall of the family history of $\mathrm{HNC}$ or other cancers would be more accurate in patients with oral cancers than that of control cancer free patients [19]. Third, the exact site of cancer for both GFHC and FHHNC was not provided. Therefore, the association of the family history of each specific site with oral cancer could not be evaluated.

\section{Conclusions}

Alcohol and tobacco may be associated with the increased risk of oral squamous cell carcinoma. Further investigations are needed to evaluate if the general family history of cancer and family history of head and neck cancer may increase the risk of the development of oral squamous cell carcinoma.

Author Contributions: Conceptualization, G.T., A.N., A.M. and U.R.; methodology, G.T., A.N., A.M. and U.R.; software, G.T., A.N. and A.M.; validation, G.T., A.N. and A.M.; formal analysis, G.T., A.N. and A.M.; investigation, G.T., A.N. and A.M.; resources, A.C., A.B. (Andrea Battisti), V.T. (Valentina Terenzi), M.D.M., I.R., E.B., F.D.F., D.M. (Daniela Musio), C.R.T.D.G., D.M. (Daniela Messineo), S.M., S.D.C., A.B. (Andrea Botticelli), V.V., P.M., V.T. (Vincenzo Tombolini), M.D.V., A.P. and U.R.; data curation, G.T., A.N., A.M., A.C., A.B. (Andrea Battisti), V.T. (Valentina Terenzi), M.D.M., I.R., E.B., F.D.F., D.M. (Daniela Musio), C.R.T.D.G., D.M. (Daniela Messineo), S.M., S.D.C., A.B. (Andrea Botticelli), V.V., P.M., V.T. (Vincenzo Tombolini), M.D.V., A.P. and U.R.; writing一original draft preparation, G.T., A.N. and A.M.; writing—review and editing, G.T., A.N., A.M., A.C., A.B. (Andrea Battisti), V.T. (Valentina Terenzi), M.D.M., I.R., E.B., F.D.F., D.M. (Daniela Musio), C.R.T.D.G., D.M. (Daniela Messineo), S.M., S.D.C., A.B. (Andrea Botticelli), V.V., P.M., V.T. (Vincenzo Tombolini), M.D.V., A.P. and U.R.; visualization, G.T., A.N. and A.M.; supervision, U.R., G.T., A.P., A.C., A.B. (Andrea Battisti), V.T. (Valentina Terenzi) and V.V.; project administration, U.R., G.T., S.D.C., A.B. (Andrea Botticelli), V.V., P.M., V.T. (Vincenzo Tombolini), M.D.V. and A.P. All authors have read and agreed to the published version of the manuscript.

Funding: This research received no external funding.

Conflicts of Interest: The authors declare no conflict of interest.

\section{References}

1. Ferlay, J.; Ervik, M.; Lam, F.; Colombet, M.; Mery, L.; Piñeros, M.; Znaor, A.; Soerjomataram, I.; Bray, F. Global Cancer Observatory: Cancer Today; International Agency for Research on Cancer: Lyon, France; Available online: https://gco.iarc.fr/today (accessed on 2 May 2020).

2. Bray, F.; Ferlay, J.; Soerjomataram, I.; Siegel, R.L.; Torre, L.A.; Jemal, A. Global cancer statistics 2018: Globocan estimates of incidence and mortality worldwide for 36 cancers in 185 countries. CA Cancer J. Clin. 2018, 68, 394-424. [CrossRef] [PubMed]

3. Ferlay, J.; Colombet, M.; Soerjomataram, I. Estimating the global cancer incidence and mortality in 2018: GLOBOCAN sources and methods. Int. J. Cancer. 2019, 144, 1941-1953. [CrossRef]

4. Dantas, T.S.; Barros silva, P.G.; Lima verde, M.E.Q. Role of Inflammatory Markers in Prognosis of Oral Squamous Cell Carcinoma. Asian. Pac. J. Cancer Prev. 2019, 20, 3635-3642. [CrossRef] [PubMed]

5. Dhull, A.K.; Atri, R.; Dhankhar, R.; Chauhan, A.K.; Kaushal, V. Major Risk Factors in Head and Neck Cancer: A Retrospective Analysis of 12-Year Experiences. World J. Oncol. 2018, 9, 80-84. [CrossRef] [PubMed] 
6. Warnakulasuriya, S. Causes of oral cancer-An appraisal of controversies. Br. Dent. J. 2009, 207, 471-475. [CrossRef]

7. Tenore, G.; Mohsen, A.; Rossi, A.F. Does Medication-Related Osteonecrosis of the Jaw Influence the Quality of Life of Cancer Patients? Biomedicines. 2020, 8, 95. [CrossRef]

8. Kreimer, A.R.; Clifford, G.M.; Boyle, P.; Franceschi, S. Human papillomavirus types in head and neck squamous cell carcinomas worldwide: A systematic review. Cancer Epidemiol Biomark. Prev. 2005, 14, 467-475. [CrossRef]

9. Lazos, J.P.; Piemonte, E.D.; Lanfranchi, H.E.; Brunotto, M.N. Characterization of Chronic Mechanical Irritation in Oral Cancer. Int. J. Dent. 2017, 2017, 1-7. [CrossRef]

10. Salasche, S.J. Epidemiology of actinic keratoses and squamous cell carcinoma. J. Am. Acad. Derm. 2000, 42, S4-S7. [CrossRef]

11. Petti, S. Lifestyle risk factors for oral cancer. Oral Oncol. 2009, 45, 340-350. [CrossRef]

12. Warnakulasuriya, S.; Johnson, N.W.; Van der waal, I. Nomenclature and classification of potentially malignant disorders of the oral mucosa. J. Oral Pathol. Med. 2007, 36, 575-580. [CrossRef] [PubMed]

13. Chattopadhyay, I.; Verma, M.; Panda, M. Role of Oral Microbiome Signatures in Diagnosis and Prognosis of Oral Cancer. Technol. Cancer Res. Treat. 2019, 18, 1-19. [CrossRef] [PubMed]

14. Hecht, S.S. Tobacco carcinogens, their biomarkers and tobacco-induced cancer. Nat. Rev. Cancer. 2003, 3, 733-744. [CrossRef] [PubMed]

15. World Health Organization. Global Status Report on Alcohol and Health 2018; World Health Organization: Geneva, Switzerland, 2018.

16. Marziliano, A.; Teckie, S.; Diefenbach, M.A. Alcohol-related head and neck cancer, Summary of the literature. Head Neck. 2020, 42, 732-738. [CrossRef] [PubMed]

17. Dhull, A.K.; Atri, R.; Kaushal, V. Alcohol as a risk factor in HNC, an enormous toll on the lives and communities. J. Evid. Based Med. Healthc. 2016, 3, 354-360. [CrossRef] [PubMed]

18. Chang, C.P.; Siwakoti, B.; Sapkota, A. Tobacco smoking, chewing habits, alcohol drinking and the risk of head and neck cancer in Nepal. Int. J. Cancer. 2019. [CrossRef]

19. Garavello, W.; Foschi, R.; Talamini, R. Family history and the risk of oral and pharyngeal cancer. Int. J. Cancer. 2008, 122, 1827-1831. [CrossRef]

20. Radoï, L.; Paget-bailly, S.; Guida, F. Family history of cancer, personal history of medical conditions and risk of oral cavity cancer in France: The ICARE study. BMC Cancer. 2013, 13, 560. [CrossRef]

21. Goldstein, A.M.; Blot, W.J.; Greenberg, R.S. Familial risk in oral and pharyngeal cancer. Eur. J. Cancer Part B: Oral Oncol. 1994, 30, 319-322. [CrossRef]

22. Brown, L.M.; Gridley, G.; Diehl, S.R. Family cancer history and susceptibility to oral carcinoma in Puerto Rico. Cancer 2001, 92, 2102-2108. [CrossRef]

23. World Health Organization. International Statistical Classification of Diseases and Related Health Problems; 10th Revision, vol. 2; WHO: Geneva, Switzerland, 2013; Available online: https://icd.who.int/browse10/2010/en (accessed on 29 May 2020).

24. Porter, S.; Gueiros, L.A.; Leão, J.C.; Fedele, S. Risk factors and etiopathogenesis of potentially premalignant oral epithelial lesions. Oral Surg. Oral Med. Oral Pathol. Oral Radiol. 2018, 125, 603-611. [CrossRef] [PubMed]

25. Lu, Y.; Sobue, T.; Kitamura, T. Cigarette smoking, alcohol drinking and oral cavity and pharyngeal cancer in the Japanese: A population-based cohort study in Japan. Eur. J. Cancer Prev. 2018, 27, 171-179. [CrossRef] [PubMed]

26. Moreno-lópez, L.A.; Esparza-gómez, G.C.; González-navarro, A.; Cerero-lapiedra, R.; González-hernández, M.J.; Domínguez-rojas, V. Risk of oral cancer associated with tobacco smoking, alcohol consumption and oral hygiene: A case-control study in Madrid, Spain. Oral Oncol. 2000, 36, 170-174. [CrossRef]

27. Anantharaman, D.; Marron, M.; Lagiou, P. Population attributable risk of tobacco and alcohol for upper aerodigestive tract cancer. Oral Oncol. 2011, 47, 725-731. [CrossRef]

28. Franceschi, S.; Talamini, R.; Barra, S. Smoking and drinking in relation to cancers of the oral cavity, pharynx, larynx and esophagus in northern Italy. Cancer Res. 1990, 50, 6502-6507. [PubMed]

29. Hashibe, M.; Brennan, P.; Chuang, S.C. Interaction between tobacco and alcohol use and the risk of head and neck cancer: Pooled analysis in the International Head and Neck Cancer Epidemiology Consortium. Cancer Epidemiol. Biomark. Prev. 2009, 18, 541-550. [CrossRef] 
30. Lee, Y.A.; Li, S.; Chen, Y. Tobacco smoking, alcohol drinking, betel quid chewing and the risk of head and neck cancer in an East Asian population. Head Neck. 2019, 41, 92-102. [CrossRef]

31. IARC Working Group on the Evaluation of Carcinogenic Risks to Humans, World Health Organization, and International Agency for Research on Cancer. Tobacco smoke. In Tobacco Smoke and Involuntary Smoking; Iarc: Lyon, France, 2004.

32. Maasland, D.H.; Van den brandt, P.A.; Kremer, B.; Goldbohm, R.A.; Schouten, L.J. Alcohol consumption, cigarette smoking and the risk of subtypes of head-neck cancer: Results from the Netherlands Cohort Study. BMC Cancer. 2014, 14, 187. [CrossRef]

33. Warnakulasuriya, S.; Dietrich, T.; Bornstein, M.M. Oral health risks of tobacco use and effects of cessation. Int. Dent. J. 2010, 60, 7-30.

34. Varoni, E.M.; Lodi, G.; Iriti, M. Ethanol versus Phytochemicals in Wine: Oral Cancer Risk in a Light Drinking Perspective. Int. J. Mol. Sci. 2015, 16, 17029-17047. [CrossRef]

35. Ferlay, J.; Steliarova-foucher, E.; Lortet-tieulent, J. Cancer incidence and mortality patterns in Europe: Estimates for 40 countries in 2012. Eur. J. Cancer. 2013, 49, 1374-1403. [CrossRef] [PubMed]

36. Mashberg, A.; Boffetta, P.; Winkelman, R.; Garfinkel, L. Tobacco smoking, alcohol drinking and cancer of the oral cavity and oropharynx among U.S. veterans. Cancer. 1993, 72, 1369-1375. [CrossRef]

37. Guilford, J.M.; Pezzuto, J.M. Wine and Health: A Review. Am. J. Enol. Vitic. 2011, 62, 471-486. [CrossRef]

38. Iriti, M.; Varoni, E.M. Cardioprotective effects of moderate red wine consumption: Polyphenols versus Ethanol. J. Appl. Biomed. 2014, 12, 193-202. [CrossRef]

39. Chuang, S.C.; Jenab, M.; Heck, J.E. Diet and the risk of head and neck cancer: A pooled analysis in the inhance consortium. Cancer Causes Control 2012, 23, 69-88. [CrossRef] [PubMed]

40. Pimenta, A.M.; Toledo, E.; Rodriguez-diez, M.C. Dietary indexes, food patterns and incidence of metabolic syndrome in a Mediterranean cohort: The SUN project. Clin. Nutr. 2015, 34, 508-514. [CrossRef]

41. Yu, G.P.; Zhang, Z.F.; Hsu, T.C.; Spitz, M.R.; Schantz, S.P. Family history of cancer, mutagen sensitivity and increased risk of head and neck cancer. Cancer Lett. 1999, 146, 93-101. [CrossRef]

42. Goldgar, D.E.; Easton, D.F.; Cannon-albright, L.A.; Skolnick, M.H. Systematic population-based assessment of cancer risk in first-degree relatives of cancer probands. J. Natl. Cancer Inst. 1994, 86, 1600-1608. [CrossRef]

43. Foulkes, W.D.; Brunet, J.S.; Kowalski, L.P.; Narod, S.A.; Franco, E.L. Family history of cancer is a risk factor for squamous cell carcinoma of the head and neck in Brazil: A case-control study. Int. J. Cancer. 1995, 63, 769-773. [CrossRef]

44. Negri, E.; Boffetta, P.; Berthiller, J. Family history of cancer: Pooled analysis in the International Head and Neck Cancer Epidemiology Consortium. Int. J. Cancer. 2009, 124, 394-401. [CrossRef]

45. Pelucchi, C.; Gallus, S.; Garavello, W.; Bosetti, C.; La vecchia, C. Cancer risk associated with alcohol and tobacco use: Focus on upper aero-digestive tract and liver. Alcohol. Res. Health 2006, 29, 193-198. [PubMed] 